This item was submitted to Loughborough's Research Repository by the author.

Items in Figshare are protected by copyright, with all rights reserved, unless otherwise indicated.

\title{
Electroluminescent light sources via soft lithography
}

PLEASE CITE THE PUBLISHED VERSION

http://dx.doi.org/10.1108/03056120810896218

PUBLISHER

(C) Emerald

VERSION

AM (Accepted Manuscript)

LICENCE

CC BY-NC-ND 4.0

REPOSITORY RECORD

Young, R.J.H., Peter S.A. Evans, Gareth I. Hay, Darren J. Southee, and David J. Harrison. 2019.

"Electroluminescent Light Sources via Soft Lithography". figshare. https://hdl.handle.net/2134/8472. 
This item was submitted to Loughborough's Institutional Repository (https://dspace.lboro.ac.uk/) by the author and is made available under the following Creative Commons Licence conditions.

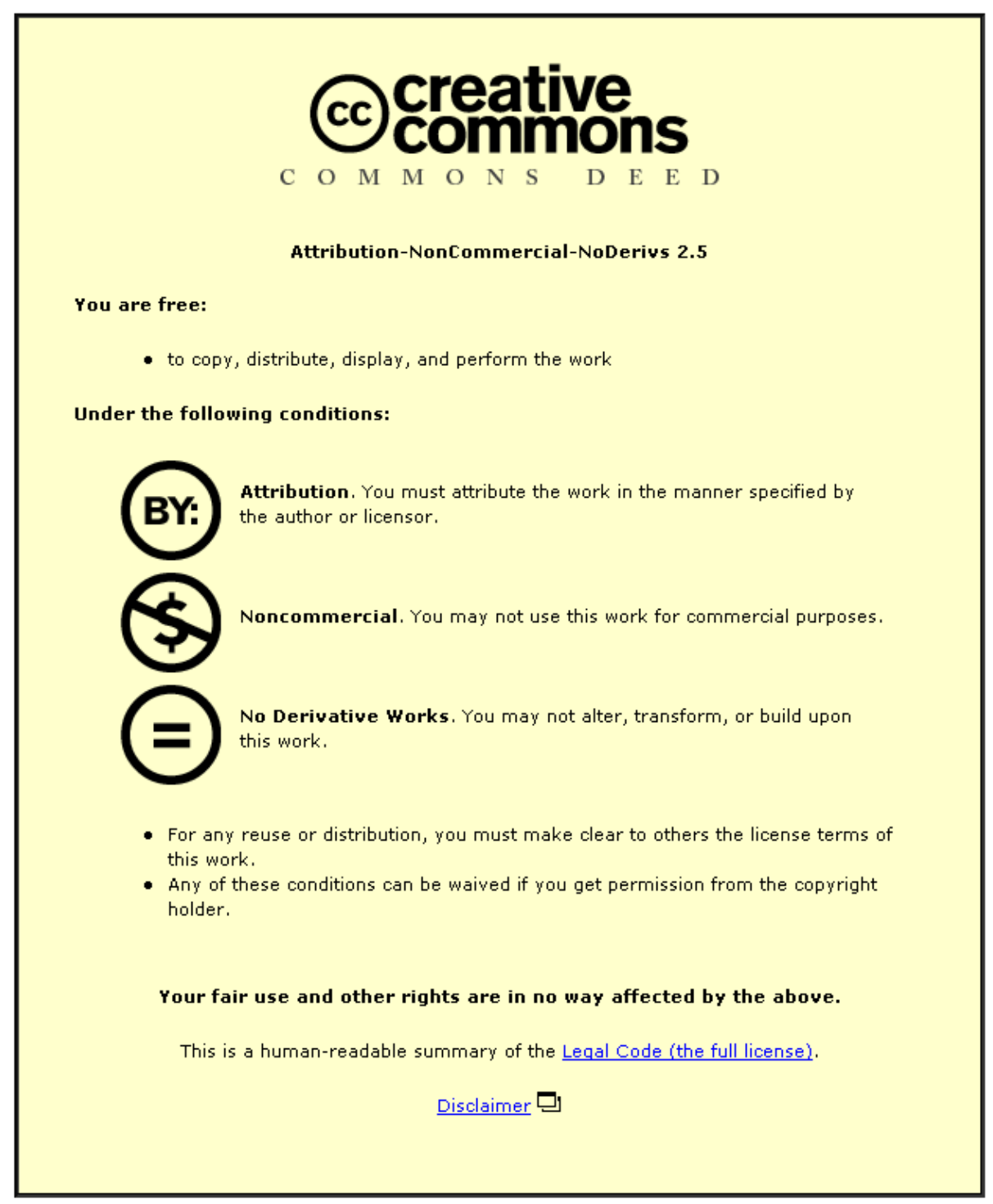

For the full text of this licence, please go to: http://creativecommons.org/licenses/by-nc-nd/2.5/ 


\title{
Electroluminescent Light Sources Via Soft Lithography
}

\author{
R. J. H. Young*, P. S. A. Evans, G. I. Hay, D. J. Southee \& D. J. Harrison \\ Cleaner Electronics Research Group, School of Engineering and Design, Brunel University, Uxbridge, Middlesex, UB8 \\ 3PH, U.K. \\ *Richard.Young@brunel.ac.uk,+44 (0) 1895274000
}

\begin{abstract}
Purpose: Microcontact printing is a process used to print high resolution protein arrays for biosensors. We investigate using these techniques to print electrically conductive fine line structures for electroluminescent (E/L) light sources.
\end{abstract}

Approach: The viability of using microcontact printing as a process for electronics fabrication is investigated. Polydimethylsiloxane (PDMS) stamps inked with alkanethiol compounds form Self Assembled Monolayers (SAM) on substrate surfaces, acting as the resist to subsequent etching processes. The printed lines are characterized with regard to their performance as high electric field generators in electroluminescent displays.

Findings: It has been demonstrated that microcontact printing is a cheap, repeatable process for fabricating electronic devices. The results demonstrate the viability of the process to fabricate electric field generator structures for E/L light sources with reduced driving voltages.

Value: It has been demonstrated that microcontact printing can produce electrically conductive fine-line structures with high resolution, confirming its viability in printed electronics manufacture.

Indexing Terms:- Microcontact Printing, Soft Lithography, Printed Displays, Printed Films, ElectroLuminescent, Phosphor Inks.

Classification:- Research paper

\section{Introduction:-}

Electroluminescent light sources utilise 'phosphor' materials that emit light when stimulated by alternating electrostatic fields, the light output being proportional to the rate-ofchange of the field. In conventional electroluminescent devices, a layer of phosphor powder is sandwiched between a transparent membrane that is coated in a transparent electrical conductor (e.g. indium-doped tin oxide (ITO)) and a dielectric layer. An electrically conductive paste (e.g. silver) is deposited on top of the dielectric layer to complete the device. When an alternating voltage is applied between the ITO and conductive backing layers a strong electric field is established in the region filled with phosphor powder. Light produced by this excitation is emitted via the transparent ITO coated substrate.

Electroluminescent light sources have found widespread application in:

- Backlighting for LCD displays,

- Low-intensity lighting systems,

- Large-area advertising displays.
Conventional electroluminescent light sources are expensive to manufacture, the high costs stem from:

- A multi-stage manufacturing process involving screen printing and curing the individual layers forming the device,

- The use of transparent electrical conductors such as ITO, which are expensive,

- The relatively thick $(\approx 100 \mu \mathrm{m})$ phosphor layers deposited by the screen-printing process (E/L phosphor materials are also expensive). (Relatively thick layers are also necessary in conventional $\mathrm{E} / \mathrm{L}$ devices to reduce the formation of pinholes in the phosphor/dielectric layers that could cause the device to break down and fail in operation).

Another factor is the relatively high voltage that must be applied to devices in operation. E/L phosphors operate effectively at applied field strengths of $\approx 10^{6}$ volts/metre, and to achieve this in sandwich structures where the electrode 
separation exceeds $100 \mu \mathrm{m}$, potentials in excess of 100 volts must be applied. High voltages are incompatible with most modern electronic circuits and systems and require that specialised voltage convertor circuits and high-voltage construction techniques are employed. Previous work within our group has explored the potential of interdigitated electrode structures to generate the electric field required by $\mathrm{E} / \mathrm{L}$ phosphor materials [2].

\section{Background:-}

"Micro-Contact Printing" is a technique for fabricating extremely high resolution structures via a self assembling monolayer and etch-resist process. The process is more economic and offers higher resolution than photolithographic processes and standard printing techniques [3], and entails depositing a self-assembling mono-molecular layer of a thiol (e.g. mercaptoundecanoic acid) onto an electrically conductive gold film previously deposited onto a glass substrate. Patterning of the gold layer is achieved by depositing the thiol using a polymer stamp whose surface is inked by immersion in a solution of the alkanethiol. The stamp contains the pattern to be formed on the substrate in relief, and transient contact between the stamp and the gold-coated substrate initially transfers the thiol to the substrate surface in the shape of the required structure.

Following the removal of the stamp, the deposited thiol self-assembles into a cohesive mono-molecular film by bonding to the gold substrate. This film is utilised as a resist layer in a subsequent etching operation that removes the exposed gold on the substrate surface in those areas not protected by the thiol monolayer.

The principle advantage of the microcontact process is very high resolution [4]. Providing a mechanically stable and high-resolution stamp is used to deposit the thiol film, gold films can be patterned on (for example) glass substrates with a minimum feature size below $20 \mu \mathrm{m}$. Our initial work therefore concerned modelling the deformation of PDMS (Polydimethylsiloxane), a polymer material cited as a stamp material in related work in soft lithography [5]. It was reported that this polymer can produce high resolution structures in moulding operations and our initial task was to confirm the stability of cured PDMS in stamping fine-line structures using finite-element analysis.

This preliminary phase of work established a nominal limit to the minimum track-and-gap spacing of printable line structures $(\approx 20 \mu \mathrm{m})$ and established that structures manufactured from PDMS with feature sizes of this order were unlikely to exhibit significant distortion when employed in stamping if the profile of the stamp features did not exceed $\approx 10 \mu \mathrm{m}$.

\section{Method:-}

Our next task concerned manufacturing a range of stamps for printing trials. Following consultations with the Scottish Microelectronics Centre, a series of moulds formed from plasmaetched silicon wafers were manufactured at their facility within Edinburgh University. The processed wafer surfaces contained mould patterns for a range of interdigitated line structure moulds designed by our group. The track and gap spacings ranged between 10 and $100 \mu \mathrm{m}$. Each mould possessed a vertical profile that extended $10 \mu \mathrm{m}$ into the wafer surface.

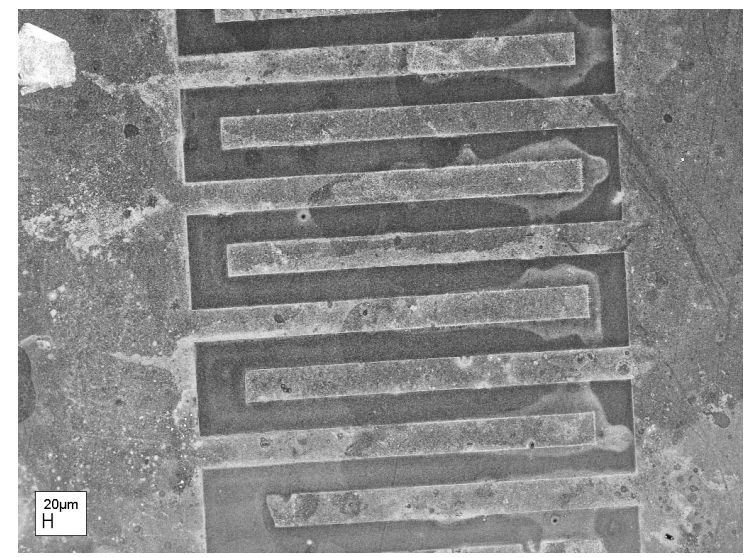

Figure 1: Interdigitated Line Structure

Stamps were cast from the surface of the wafer using a moulding/curing process and liquid PDMS monomer. Following curing, the PDMS layer was detached from the wafer surface and the various stamp regions, (consisting of interdigitated line structures raised from the stamp surface by $10 \mu \mathrm{m}$ in relief), were removed by sectioning. The finished stamps were immersed in a $1 \mathrm{mmol} / \mathrm{l}$ solution of thiol for 2 hours, and the stamps manually applied to the surface of gold coated glass substrates.

Following the stamping procedure and the deposition of a thiol resist layer the substrates were etched using a purpose-developed iodinebased solution that avoided the need for cyanide compounds. The etch rate of the process was $\leq$ $1 \mu \mathrm{m} / \mathrm{min}$, which was reduced by diluting the solution to $30 \%$ of its original strength using deionized water. The resulting gold interdigitated 
line structures (figure 1) were examined by optical and electron microscopy and selected structures coated with an electroluminescent phosphor powder suspended in an air-curing alkyd resin binder. The binder acted to mechanically bond the phosphor to the surface of the structure formed a dielectric medium to increase the electric field strength in the region of the embedded phosphor powder.

\section{Results:-}

The completed structures were examined by applying an excitation voltage generated using a variable-frequency variable-voltage power supply (a Newtons 4th power amplifier type LPA400), and the emitted light analysed by a Jeti Specbos 1201 Spectroradiometer. Light output from electroluminescent phosphor materials is proportional to the rate-of-change of the applied electric field, which is proportional to the magnitude of applied driving voltage and its frequency. Specimen plots of stimulus voltage against luminance at various driving frequencies are given in figure 2 . These results were reported in [6], [7].

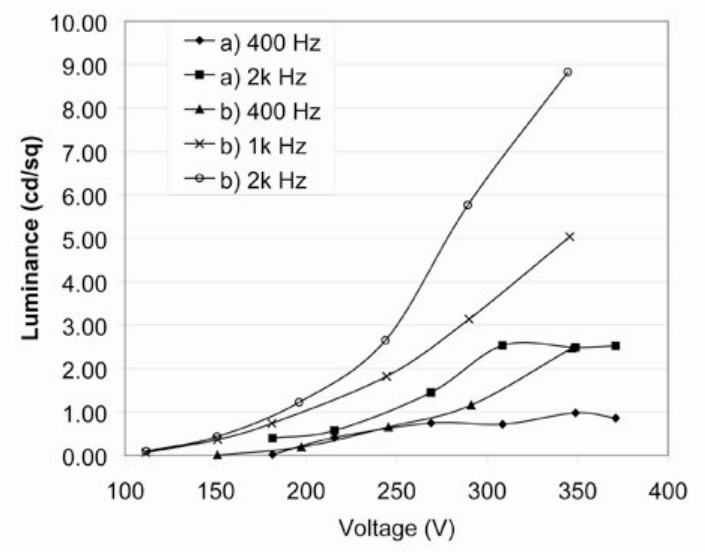

Figure 2: Luminance/Voltage Plots

The luminance/voltage plot figure 2 contains data from two similar electroluminescent structures $a$ and $b$. Structure a was found to emit light at an initial stimulating voltage of $\approx 180 \mathrm{~V}$, compared with structure $b$ which required $\approx 110 \mathrm{~V}$ before the structure emitted light. This indicates an increased electric field is being generated within structure $b$ for a given driving voltage. Plots $a$ and $b$ were however both obtained from structures with a nominal $75 \mu \mathrm{m}$ track and gap spacing.

The observed spread of characteristics is ascribed to manufacturing tolerances currently encountered of manufacturing due to the apparent difference in light output between the structures is caused by the area.

Viable structures of $25 \mu \mathrm{m}$ track and gap were also manufactured and evaluated. However the total resistance of these line structures is increased due to the tracks being three times the length introducing a sheet resistance nine times the size of a $75 \mu \mathrm{m}$ track and gap structure.

\section{Conclusions:-}

Microcontact printing has been employed to print high-resolution interdigitated electrode structures that can be used as electric field generators. These structures were employed in prototype electroluminescent light devices formed by depositing $\mathrm{E} / \mathrm{L}$ phosphor materials between the electrodes. By reducing the track and gap spacing toward the limit of the resolution achievable with the microcontact process $(\approx 10 \mu \mathrm{m})$ the stimulating voltage of these structures is significantly reduced.

\section{Future Work:-}

Work is currently being directed towards improving both the characteristics of the alkanethiol resist layer and the current etching technique to improve the yield of functional devices. Attention is also being given to utilising an additive plating process in conjunction with the microcontact printing process, whereby metal is deposited on the substrate only where necessary and avoiding the need for an etching process. The advantages of additive circuit manufacturing processes are detailed in [1].

\section{Acknowledgements:-}

We acknowledge assistance in this Project from: Dr. D.A. Hutt (Loughborough University) and from Gwent Electronic Materials (Monmouthshire). This research was funded by the IeMRC initiative.

\section{References:-}

[1] B.J. Ramsey, P.S.A. Evans \& D.J. Harrison. Journal of Electronic Manufacturing, Vol. No.7, No.1. March 1997. pp 63 - 67. "A Novel Fabrication Technique Using Offset Lithography".

[2] J. Silver, R. Withnall, G.R. Fern, P. J. Marsh, T.G. Ireland, P.G. Harris, P.S.A. Evans, D.J. Southee, G. Hay, D.J. Harrison \& K.F.B. Breen. Asia Display 2007. The Fabrication of Miniaturised Electrode Circuitry by Offset 
Lithographic Printing for Novel Electroluminescent Displays.

[3] Y. Xia \& G.M. Whitesides. Annual Review of Material Science, 1998. Vol. 28. pp 153-184 "Soft Lithography".

[4] "Printing meets lithography: Soft approaches to high-resolution patterning". IBM Research \& Development. Vol. 45, No. 5. September 2001.

[5] Whitesides (et al.), U.S. patent No. 6,776,094B1, August 17, 2004.

[6] R. Young, P.S.A. Evans \& D.J. Harrison. Manufacturing Electronic Devices Using Embossing \& Microcontact Printing. IeMRC Conference, Loughborough University, September 2007.

[7] R. Young \& P.S.A. Evans. Manufacturing Electronic Devices Via Soft Lithography UK Displays \& Lighting KTN. Gregynog-Newtown, Wales. April 2008. 